\title{
Maternal serum IL-22 concentrations are significantly upregulated in patients with preterm premature rupture of membranes
}

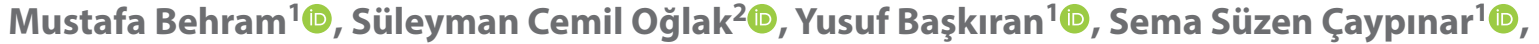

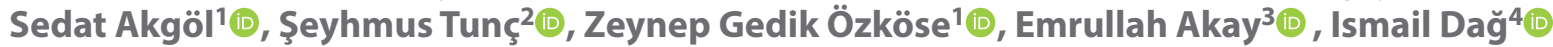 \\ ${ }^{1}$ Department of Obstetrics and Gynecology, Health Sciences University, Kanuni Sultan Süleyman Training and Research Hospital, \\ Istanbul, Turkey \\ ${ }^{2}$ Department of Obstetrics and Gynecology, Health Sciences University, Gazi Yaşargil Training and Research Hospital, Diyarbakır, Turkey \\ ${ }^{3}$ Department of Obstetrics and Gynecology, Başakşehir Çam and Sakura City Hospital, Istanbul, Turkey \\ ${ }^{4}$ Department of Biochemistry, Eyüpsultan State Hospital, Istanbul, Turkey
}

\begin{abstract}
Objectives: This study aimed to compare the serum IL-22 levels between preterm premature rupture of membranes (PPROM) patients and the control group with intact membranes. We also hypothesized whether serum IL-22 upregulation might contribute to defense against inflammatory responses and improve the pregnancy outcomes.

Material and methods: We performed this prospective case-control study between 24-34 weeks of pregnancy. We enrolled 40 singleton pregnant patients with PPROM and 40 healthy gestational age- and gravidity-matched patients without PPROM. The degree of association between variables and IL-22 were calculated by Spearman correlation coefficients where appropriate. Scatter plots were given for statistically significant correlations. ROC curve was constructed to illustrate the sensitivity and specificity performance characteristics of IL-22, and a cutoff value was estimated by using the index of Youden.

Results: Maternal serum IL-22 levels were significantly higher in PPROM patients $(60.34 \pm 139.81 \mathrm{pg} / \mathrm{mL})$ compared to the participants in the control group $(20.71 \pm 4.36 \mathrm{pg} / \mathrm{mL}, \mathrm{p}<0.001)$. When we analyze the area under the ROC curve (AUC), the IL-22 value can be considered a statistically significant parameter for diagnosing PPROM. According to the Youden index, a $23.86 \mathrm{pg} / \mathrm{mL}$ cut-off value of IL-22 can be used to diagnosing PPROM with $72 \%$ sensitivity and $61.5 \%$ specificity. There was no positive correlation between serum IL-22 levels and maternal C-reactive protein (CRP) value, procalcitonin value, latency period, birth week, birth weight, and umbilical cord blood $\mathrm{pH}$ value.

Conclusions: Maternal serum IL-22 levels were significantly higher in PPROM patients than healthy pregnant women with an intact membrane. We suggest that IL-22 might be a crucial biomarker of the inflammatory process in PPROM.
\end{abstract}

Key words: preterm premature rupture of membranes; interleukin-22; neonatal outcomes

Ginekologia Polska 2021; 92, 9: 631-636

\section{INTRODUCTION}

Preterm premature rupture of membranes (PPROM) is described as rupture of the amniotic membranes before 37 weeks of gestation [1]. This common obstetrical syndrome complicates approximately $3-4 \%$ of all pregnancies and is the identifiable leading cause of preterm birth, with about $40 \%$ of preterm deliveries being associated with PPROM [2]. PPROM is related to short-latency from membrane rupture to labor, infectious complications, and adverse neonatal outcomes associated with preterm birth [3]. These adverse outcomes include neonatal mortality and long-term complications of surviving neonates. Preterm labor is the single direct cause in $35 \%$ of neonatal deaths. Surviving neonates often experience long-term consequences, including numerous physical effects (cardiovascular disease, chronic lung disease, hearing or visual impairment), behavioral deficiencies, and neurodevelopmental delay [4]. These complications represent a substantial burden for the family, healthcare system, and society [5].

\footnotetext{
Corresponding author:

Süleyman Cemil Oğlak

Department of Obstetrics and Gynecology, Health Sciences University, Gazi Yaşargil Training and Research Hospital, Diyarbakır, Turkey

e-mail: sampson_21@hotmail.com
}

This article is available in open access under Creative Common Attribution-Non-Commercial-No Derivatives 4.0 International (CC BY-NC-ND 4.0) license, allowing to download articles and share them with others as long as they credit the authors and the publisher, but without permission to change them in any way or use them commercially. 
Also, neonatal morbidity and mortality rates are higher in PPROM patients than the other subgroups of preterm deliveries [6]. Therefore, it is crucial to determine the mechanisms implicated in PPROM and develop innovative treatments and strategies to prevent or manage this syndrome.

During a healthy pregnancy, the maternal immune system must prosecute in a delicate balancing act as maintaining tolerance to the fetal allograft while preserving adaptive and innate immune mechanisms for protection against microbial infections [7, 8]. Infection and inflammation are implicated in the pathogenesis of PPROM. An imbalance in the production of anti-inflammatory and pro-inflammatory cytokines may activate different humoral and cellular immunologic components, amplifying the membrane weakening and damage. PPROM is considered a disease of the fetal membranes. The inflammation-oxidative stress axis acts a significant role in producing pathways that can cause membrane weakening by several processes, including the activation of matrix-degrading proteases that lyse the collagens and increasing the production of cytokines and prostaglandins [9]. Histological chorioamnionitis (HCA) being reported in about $40-70 \%$ of PPROM patients [10]. Immediate and correct HCA diagnosis is essential; however, the event restricts that placental pathology can only be assessed after delivery [11].The inflammatory response can also be shown in the amniotic fluid and maternal and fetal serum. Previous studies reported that HCA is associated with increased maternal and fetal serum levels of pro-inflammatory cytokines, including interleukin-1 beta (IL-1 ), IL-2, IL-6, IL-8, IL-22, and tumor necrosis factor-alpha (TNF-a) [12].

IL-22 is a clinically relevant cytokine, mostly secreted by immune cells, including innate lymphoid cells (ILC), natural killer cells, T-helper 1 (Th1) cells, Th17 cells, Th22 cells, and lymphoid tissue inducer cells [13]. IL-22 is capable of mediating both pro-inflammatory and anti-inflammatory responses, promotes epithelial cell proliferation and survival of epithelial cells, wound repair, and induces the secretion of antimicrobial proteins [14]. However, it remains unclear if IL-22 upregulation might be associated with the pathological processes of the PPROM or it performs a different function. In a recent study, the authors suggested that IL-22 prevents preterm birth and promotes epithelial cell regeneration [15].

In this study, we aimed to compare the serum IL-22 levels between PPROM patients and the control group with intact membranes. We also hypothesized whether serum IL-22 upregulation might contribute to defense against inflammatory responses and improve pregnancy outcomes.

\section{MATERIAL AND METHODS}

We performed this prospective case-control study in Kanuni Sultan Süleyman Training and Research Hospital Hospital from July 2019 to January 2020. This study was approved by the Ethics Committee of the same hospital. Informed consent forms were obtained from all participants. All the pregnant women were between the age of 18-40 years and $24^{0 / 7}-34^{0 / 7}$ weeks of gestation. Of the 80 pregnant women included in the study, we enrolled 40 singleton pregnant patients with PPROM as the study group and 40 healthy gestational age-, gravidity-, and body mass index (BMI)-matched patients without PPROM as the control group. The control group consisted of patients who did not experience any complications associated with pregnancy in the later gestational weeks and had given birth at term.

Patients admitted to our hospital with the complaint or suspicion of PPROM were assessed in the emergency department according to the ACOG criteria [16]. We diagnosed PPROM by using a sterile speculum to evaluate the amniotic fluid leakage from the cervix uteri and then examined utilizing Amnisure ${ }^{\circ}$, a rapid test based on the Placental Alpha Microglobulin-1 (PAMG-1) detection in high concentrations in amniotic fluid [17]. The gestational week was determined by sonographic measurement and confirmed according to the last menstrual period and a first-trimester ultrasound exam. Patients with a confirmed PPROM diagnosis were hospitalized and referred to our obstetric department for further evaluation and proper treatment. We collected the blood samples to measure IL-22 levels at the time of the hospitalization. We also took maternal blood samples to analyze complete blood count ( $C B C$ ) every 72 hours, evaluating clinical chorioamnionitis every eight hours after hospitalization and during the latency period [11]. All pregnant women with PPROM underwent ampicillin treatment daily to prevent chorioamnionitis and four doses of $6 \mathrm{mg}$ of betamethasone for fetal lung maturation. We used Nifedipine to delay the preterm birth during the first 48 hours in all patients.

The pregnancy termination was performed at the end of the $34^{\text {th }}$ gestational weeks or early signs of clinical chorioamnionitis. Clinical chorioamnionitis was diagnosed with the following signs: fever ( $\geq 38^{\circ} \mathrm{C}$ orally), maternal tachycardia (> 100 beats/minute), fetal tachycardia (> 160 beats/minute), leukocytosis, purulent vaginal discharge, uterine tenderness, and abdominal pain [18]. We performed labor induction by cervical ripening with a vaginal prostaglandin E2 slow-release system [19]. Indication for cesarean section for non-reassuring fetal status was based on abnormal fetal heart rate monitoring [20].

We excluded patients with gestational hypertensive disorders, hepatic disease, multiple pregnancies, anemia, infections, a history of ruptured amniotic membranes in their previous pregnancies, and co-existing morbidities, including diabetes mellitus, hypothyroidism, chronic hypertension, collagen vascular disease, renal disease, known malignancy, and ischemic heart disease. Patients with unavailable or incomplete medical records were also excluded. 
Maternal age, gravidity, parity, BMI, previous history of cesarean section, maternal serum hemoglobin value, white blood cell count (WBC), platelet value, mean corpuscular volume (MCV), red cell distribution width (RDW), C-reactive protein (CRP) value, procalcitonin value, IL-22 value, latency from membrane rupture to labor, and type of delivery (vaginal or cesarean) were recorded. The birth week, birth weight, umbilical cord blood pH, 1- and 5-minute Apgar scores of the newborn were also recorded.

Serum IL-22 concentration was measured using an enzyme immunoassay (Catalog Number: EK0933, Boster Biological Technology 3942 Valley Ave Pleasanton, CA 94566, USA) with a minimum detectable concentration of $15.6 \mathrm{pg} / \mathrm{mL}$ and intra- and inter-assay coefficients of variation less than $5.1 \%$ and $6.3 \%$, respectively. Absorbance at $450 \mathrm{~nm}$ was measured using an SMR 16.1 Smart Microplate Reader (USCN KIT INC.).

\section{Statistical evaluation}

We used the Kolmogorov-Smirnov and Shapiro Wilk tests to examine whether the data are normally distributed. We tested the homogeneities of variances by the Levene test. The Chi-square and/or Fisher's exact tests for categorical variables and Student's t-test or Mann-Whitney $U$ test for continuous variables were used to evaluating differences between groups. The degree of association between variables and IL-22 were calculated by Spearman correlation coefficients where appropriate. Scatter plots were given for statistically significant correlations. Receiver operating characteristic (ROC) curve was constructed to illustrate the sensitivity and specificity performance characteristics of IL-22, and a cutoff value was estimated by using the index of Youden. Frequencies (percentages), mean \pm standard deviation, and median (minimum-maximum) were given as descriptive statistics. We performed statistical analyses using IBM SPSS 20.0 for Windows (SPSS Inc., Chicago, IL, USA), and the $p$-value $<0.05$ was considered statistically significant.

\section{RESULTS}

During the study period, 89 patients were enrolled in the study, of which 45 were PPROM patients. After withholding patients with missing medical records and applying the exclusion criteria, 40 patients remained in both groups.

We presented the demographic variables, clinical characteristics, and the perinatal outcomes of the patients in Table 1. There were no significant differences between the two groups in terms of maternal age, gravidity, parity, BMI, history of a previous cesarean section, and delivery type.

Maternal serum IL-22 concentrations were significantly higher in patients with PPROM $(60.34 \pm 139.81 \mathrm{pg} / \mathrm{mL})$

Table 1. Comparison of demographic variables, clinical characteristics, and perinatal outcomes between control group and preterm premature rupture of membranes group

\begin{tabular}{|l|l|l|l|}
\hline & Control group & PPROM group & p value \\
\hline Age [years] & $28.17 \pm 5.27$ & $27.69 \pm 5.93$ & 0.702 \\
\hline Gravidity & $2.92 \pm 1.32$ & $2.82 \pm 1.68$ & 0.483 \\
\hline Parity & $1.56 \pm 1.18$ & $1.28 \pm 1.39$ & 0.143 \\
\hline BMI [kg/m²] & $27.51 \pm 3.79$ & $27.51 \pm 4.86$ & 0.997 \\
\hline Previous cesarean section, $\mathrm{n}(\%)$ & $19(47.5)$ & $14(35.0)$ & 0.252 \\
\hline IL-22 [pg/mL] & $20.71 \pm 4.36$ & $60.34 \pm 139.81$ & $<0.001$ \\
\hline CRP [mg/L] & $9.24 \pm 0.49$ & $11.30 \pm 12.40$ & 0.116 \\
\hline Procalcitonin [ng/mL] & $0.03 \pm 0.00$ & $0.04 \pm 0.02$ & $<0.001$ \\
\hline WBC [/mm $3 \times 10^{3}$ ] & $11.21 \pm 3.28$ & $12.48 \pm 3.71$ & 0.653 \\
\hline Hemoglobin [g/dL] & $11.48 \pm 0.55$ & $11.89 \pm 1.33$ & 0.116 \\
\hline Platelet $\left./ / \mathrm{mm}^{3} \times 10^{3}\right]$ & $191.82 \pm 6.62$ & $272.07 \pm 77.08$ & $<0.001$ \\
\hline MCV [fL] & $87.61 \pm 1.06$ & $84.12 \pm 6.53$ & $<0.001$ \\
\hline RDW [\%] & $13.46 \pm 0.48$ & $13.51 \pm 2.08$ & 0.289 \\
\hline Latency period [days] & $\mathrm{N} / \mathrm{A}$ & $19.05 \pm 18.00$ & $\mathrm{~N} / \mathrm{A}$ \\
\hline Cesarean birth, $\mathrm{n}(\%)$ & $22(55.0 \%)$ & $26(65.0 \%)$ & 0.352 \\
\hline Birth week & $39.15 \pm 0.77$ & $29.92 \pm 4.11$ & $<0.001$ \\
\hline Birth weight [g] & $3662.56 \pm 176.24$ & $1746.53 \pm 596.71$ & $<0.001$ \\
\hline Umbilical cord blood pH value & $7.34 \pm 0.04$ & $7.30 \pm 0.08$ & 0.007 \\
\hline 1-min Apgar & $7.66 \pm 0.66$ & $4.74 \pm 2.42$ & $<0.001$ \\
\hline 5-min Apgar & $9.41 \pm 0.49$ & $7.10 \pm 2.45$ & $<0.001$ \\
\hline PPROM- & & \\
\hline
\end{tabular}

PPROM - preterm premature rupture of membranes; BMI — body mass index; CRP — C-reactive protein; WBC — white blood cell count; MCV — mean corpuscular volume; RDW - red cell distribution width; N/A — not available 
compared to the participants in the control group $(20.71 \pm 4.36 \mathrm{pg} / \mathrm{mL}, \mathrm{p}<0.001)$. When we analyze the area under the ROC curve (AUC), the IL-22 value can be considered a statistically significant parameter for diagnosing PPROM (Tab. 2, Fig. 1). According to the Youden index, a $23.86 \mathrm{pg} / \mathrm{mL}$ cut-off value of IL-22 can be used to diagnose PPROM with $72 \%$ sensitivity and $61.5 \%$ specificity.

There was no positive correlation between serum IL-22 levels and maternal CRP value, procalcitonin value, latency period, birth week, birth weight, and umbilical cord blood $\mathrm{pH}$ value (Tab. 3).

\section{DISCUSSION}

In the current study, we evaluated the concentrations of IL-22 in the maternal serum of the patients in association with the presence or absence of PPROM. Our study indicates that IL-22 demonstrated significantly increased levels in the serum of patients suffering from PPROM than control patients with intact membranes. However, we found no significant correlation between the upregulation of maternal serum IL-22 levels and pregnancy outcomes.

Inflammation and oxidative stress are keenly associated with the pathogenesis of PPROM. These events are inducted in response to etiological factors with histochemical and biochemical results that may weaken the fetal membranes [9]. The immune mechanisms that play a role in these events may be local or systemic, namely, systemic involvement of immune factors located in circulating blood or local involvement of elements in the fetomaternal unit's layers [4, 21-23]. The amniotic fluid includes inflammatory cytokines and molecules that can be utilized as biochemical markers to predict PPROM, including IL-1, IL-6, IL-22, and TNF-a [4]. However, amniocentesis is an invasive method with concomitant jeopardies. Also, oligohydramnios due to membrane rupture frequently makes this procedure challenging to obtain the amniotic fluid [11]. Therefore, a less invasive and more straightforward procedure of examining these cytokines in maternal serum would be beneficial for the prediction of PPROM. Since PPROM is described as the disease of the fetal membranes, several placental factors and pro-inflammatory cytokines have been implicated in the PPROM pathogenesis. However, few studies investigate the role of maternal serum inflammatory markers for predicting PPROM in the literature. This prediction model is essential for the obstetric units that are not well-resourced in which there is no chance to perform invasive methods for investigating these markers in the amniotic fluid.

IL-22, an IL-10 family member, is a glycoprotein and secreted by cells of the innate and adaptive immune system [24]. The primary biological characteristics of IL-22 are pro-regenerative and anti-apoptotic properties [25].

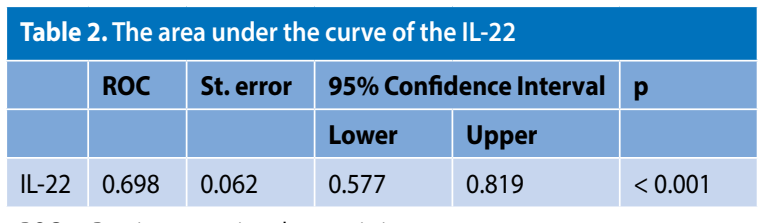

ROC - Receiver operating characteristic

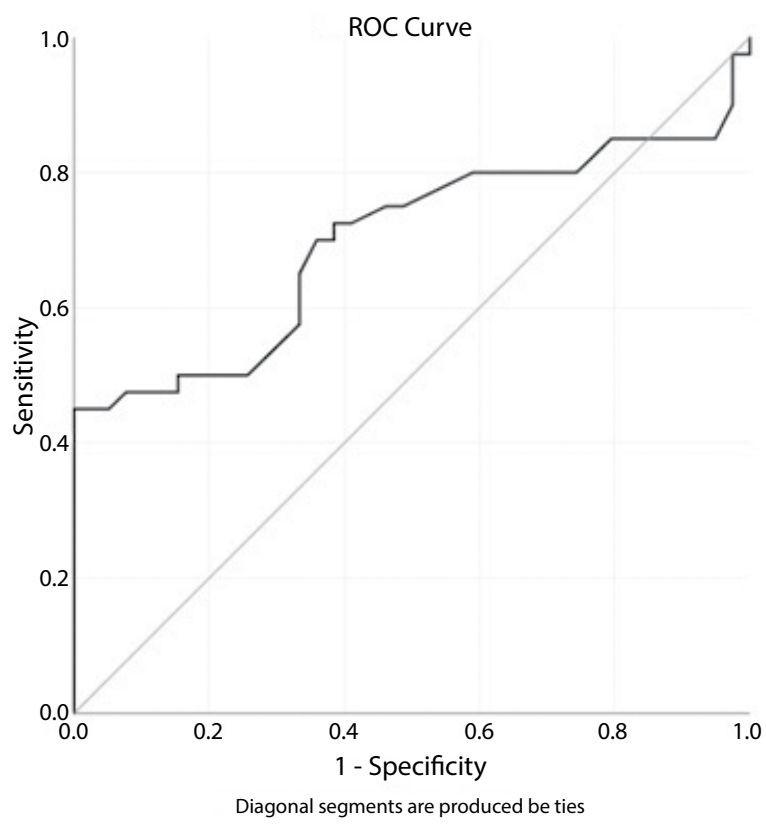

Figure 1. Receiver operating characteristic (ROC) curve for serum IL-22 concentrations in patients with preterm premature rupture of membranes

\begin{tabular}{|c|c|c|c|c|}
\hline & \multicolumn{4}{|c|}{ IL-22 } \\
\hline & & $\begin{array}{l}\text { Control } \\
(n=39)\end{array}$ & $\begin{array}{l}\text { PPROM } \\
(n=39)\end{array}$ & $\begin{array}{l}\text { All } \\
(n=78)\end{array}$ \\
\hline \multirow{2}{*}{ CRP $[\mathrm{mg} / \mathrm{L}]$} & $r$ & 0.008 & -0.016 & 0.023 \\
\hline & $p$ & 0.969 & 0.921 & 0.845 \\
\hline \multirow{2}{*}{ Procalsitonin $[\mathrm{ng} / \mathrm{mL}]$} & r & 0.021 & 0.266 & 0.158 \\
\hline & $\mathrm{p}$ & 0.897 & 0.102 & 0.167 \\
\hline \multirow{2}{*}{ Latency period [days] } & r & $\mathrm{N} / \mathrm{A}$ & -0.015 & -0.015 \\
\hline & $p$ & N/A & 0.926 & 0.926 \\
\hline \multirow{2}{*}{ Birth week } & $r$ & -0.116 & -0.207 & -0.129 \\
\hline & $\mathrm{p}$ & 0.482 & 0.205 & 0.261 \\
\hline \multirow{2}{*}{ Birth weight } & $r$ & -0.067 & -0.186 & -0.107 \\
\hline & $p$ & 0.684 & 0.257 & 0.352 \\
\hline \multirow{2}{*}{$\begin{array}{l}\text { Umbilical cord blood } \\
\text { pH value }\end{array}$} & $r$ & -0.062 & -0.303 & -0.212 \\
\hline & $p$ & 0.708 & 0.061 & 0.062 \\
\hline \multirow{2}{*}{ 1-min Apgar } & $r$ & -0.029 & -0.264 & -0.158 \\
\hline & $\mathrm{p}$ & 0.861 & 0.104 & 0.166 \\
\hline \multirow{2}{*}{ 5-min Apgar } & $r$ & 0.125 & -0.165 & -0.071 \\
\hline & $p$ & 0.448 & 0.315 & 0.536 \\
\hline
\end{tabular}

CRP - C-reactive protein; N/A — not available 
IL-22 has been demonstrated to modulate the secretion of numerous genes encoding proteins involved in tissue protection, differentiation, remodeling, and survival, and to a more secondary amount, pro-inflammatory proteins [26]. Previous studies reported that IL-22 plays a pivotal role in several immune-mediated inflammatory diseases such as inflammatory bowel diseases, rheumatoid arthritis, psoriasis, and allergic diseases [24].

IL-22 acts primarily in epithelial and stromal cells. In human pregnancy, trophoblast cells are epithelial cells that stemmed fetal origin and promote pregnancy maintenance. Wang et al. stated that IL-22 enhances cell viability, promotes proliferation, and decreases the apoptosis of trophoblast cells. They suggested that IL-22 might be a useful cytokine for the completion of gestation [27]. Dambaeva et al. [14], indicated that IL-22 is upregulated in response to lipopolysaccharide (LPS) injection into pregnant mice's uterus and proposes the probable administration of IL-22 to control inflammation-induced preterm delivery [15]. They also stated that LPS-induced pregnancy loss and fetal death risk in IL-22 k/o mice were significantly reduced with recombinant IL-22 (rIL-22) injection. Moreover, rIL-22 injection inhibited LPS-triggered preterm delivery in an IL-22 +/+ mice. Xu et al. [28] suggested that ILCs are implicated in the localized inflammatory milieu that accompanies preterm birth pathogenesis by expressing a high level of IL-22. Our study showed that maternal serum IL-22 concentrations were higher in women with PPROM $(60.34 \pm 139.81 \mathrm{pg} / \mathrm{mL})$ than in the control group $(20.71 \pm 4.36 \mathrm{pg} / \mathrm{mL}, \mathrm{p}<0.001)$. We think that this result conclusively demonstrated the inflammation in the pathological process of PPROM.

We also assessed whether there is a relationship between maternal serum IL-22 concentration and latency period and neonatal outcomes, including birth week, birth weight, umbilical cord blood $\mathrm{pH}$ value, 1- and 5-minute Apgar scores. We found no correlation between maternal serum IL-22 levels and neonatal outcomes. Aris et al. [29] concluded that PPROM in the previous gestation is related to significant adverse neonatal outcomes in the subsequent gestation. We exclude all patients with a history of PPROM to eliminate this risk factor. Martinez-Portilla et al. and Sorokin et al. found no significant association between maternal serum inflammatory markers and adverse neonatal outcomes [11, 30].

To the best of our knowledge, this is the first study to date that has assessed the serum IL-22 concentrations in PPROM patients and compared with healthy pregnant women with intact membranes. Also, we included the control and PPROM patient groups that were matched for maternal age, gestational age at blood sample collection, or BMI.
As IL-22 levels may vary with these factors, we eliminate the ones that could introduce potential bias.

This study's main limitation is the absence of confirming the inflammation by the histopathological examination after birth. Further studies are required in which the association between maternal serum IL-22 levels and clinical outcomes are confirmed by postnatal histopathological evaluation.

\section{CONCLUSIONS}

Maternal serum IL-22 levels were significantly higher in PPROM patients than healthy pregnant women with an intact membrane. We suggest that IL-22 might be a crucial biomarker of the inflammatory process in PPROM. However, there was no positive correlation between serum IL-22 levels and maternal CRP value, procalcitonin value, latency period, birth week, birth weight, and umbilical cord blood pH value.

\section{Conflict of interest}

The authors declared no conflict of interest.

\section{REFERENCES}

1. Modi BP, Parikh HI, Teves ME, et al. Discovery of rare ancestry-specific variants in the fetal genome that confer risk of preterm premature rupture of membranes (PPROM) and preterm birth. BMC Med Genet. 2018; 19(1): 181, doi: 10.1186/s12881-018-0696-4, indexed in Pubmed: 30290772.

2. Cobo T, Kacerovsky M, Palacio $M$, et al. Intra-amniotic inflammatory response in subgroups of women with preterm prelabor rupture of the membranes. PLoS One. 2012; 7(8): e43677, doi: 10.1371/journal. pone.0043677, indexed in Pubmed: 22916296.

3. Mercer BM, Crouse DT, Goldenberg RL, et al. Eunice Kennedy Shriver National Institute of Child Health and Human Development Maternal-Fetal Medicine Units Network. The antibiotic treatment of PPROM study: systemic maternal and fetal markers and perinatal outcomes. Am J Obstet Gynecol. 2012; 206(2): 145.e1-145.e9, doi: 10.1016/j.ajog.2011.08.028, indexed in Pubmed: 22000668.

4. Gilman-Sachs A, Dambaeva S, Salazar Garcia MD, et al. Inflammation induced preterm labor and birth. J Reprod Immunol. 2018; 129: 53-58, doi: 10.1016/j.ji.2018.06.029, indexed in Pubmed: 30025845.

5. Chang HH, Larson J, Blencowe $\mathrm{H}$, et al. Born Too Soon preterm prevention analysis group. Preventing preterm births: analysis of trends and potential reductions with interventions in 39 countries with very high human development index. Lancet. 2013; 381(9862): 223-234, doi: 10.1016/S0140-6736(12)61856-X, indexed in Pubmed: 23158883.

6. Baran ŞY, Törer B, Kalaycı H, et al. The Effect of the Cause of Delivery on Neonatal Outcomes in Early Preterm Deliveries. Journal of Fetal Medicine. 2019; 6(3): 139-145, doi: 10.1007/s40556-019-00214-w.

7. Aghaeepour N, Ganio EA, Mcilwain D, et al. An immune clock of human pregnancy. Sci Immunol. 2017; 2(15), doi: 10.1126/sciimmunol. aan2946, indexed in Pubmed: 28864494.

8. Oğlak SC, Aydın MF. Are neutrophil to lymphocyte ratio and platelet to lymphocyte ratio clinically useful for the prediction of early pregnancy loss? Ginekol Pol. 2020; 91(9): 524-527, doi: 10.5603/GP.a2020.0082, indexed in Pubmed: 33030732.

9. Menon R, Richardson LS. Preterm prelabor rupture of the membranes: A disease of the fetal membranes. Semin Perinatol. 2017; 41(7): 409-419, doi: 10.1053/j.semperi.2017.07.012, indexed in Pubmed: 28807394.

10. Tita ATN, Andrews WW. Diagnosis and management of clinical chorioamnionitis. Clin Perinatol. 2010; 37(2): 339-354, doi: 10.1016/j. clp.2010.02.003, indexed in Pubmed: 20569811.

11. Martinez-Portilla RJ, Hawkins-Villarreal A, Alvarez-Ponce P, et al. Maternal Serum Interleukin-6: A Non-Invasive Predictor of Histological Chorioamnionitis in Women with Preterm-Prelabor Rupture of Membranes. Fetal Diagn Ther. 2019; 45(3): 168-175, doi: 10.1159/000488080, indexed in Pubmed: 29635237. 
12. Bersani I, De Carolis MP, Foell D, et al. Interleukin-22: biomarker of maternal and fetal inflammation? Immunol Res. 2015; 61(1-2): 4-10, doi: 10.1007/s12026-014-8568-2, indexed in Pubmed: 25407645.

13. Witte $E$, Witte $K$, Warszawska $K$, et al. Interleukin-22: a cytokine produced by T, NK and NKT cell subsets, with importance in the innate immune defense and tissue protection. Cytokine Growth Factor Rev. 2010; 21(5): 365-379, doi: 10.1016/j.cytogfr.2010.08.002, indexed in Pubmed: 20870448.

14. Dudakov JA, Hanash AM, van den BrinkMRM. Interleukin-22: immunobiology and pathology. Annu Rev Immunol. 2015;33:747-785, doi: 10.1146/annurev-immunol-032414-112123, indexed in Pubmed: 25706098.

15. Dambaeva S, Schneiderman S, Jaiswal MK, et al. Interleukin 22 prevents lipopolysaccharide- induced preterm labor in mice. Biol Reprod. 2018; 98(3): 299-308, doi: 10.1093/biolre/iox182, indexed in Pubmed: 29315356.

16. Committee on Practice Bulletins-Obstetrics. ACOG Practice Bulletin No. 188: Prelabor Rupture of Membranes. Obstet Gynecol. 2018; 131(1): e1-e14, doi: 10.1097/AOG.0000000000002455, indexed in Pubmed: 29266075.

17. Abdelazim IA, Makhlouf HH. Placental alpha microglobulin-1 (AmniSure $\left.{ }^{\oplus}\right)$ test) for detection of premature rupture of fetal membranes. Arch Gynecol Obstet. 2012; 285(4): 985-989, doi: 10.1007/s00404-011-2106-4, indexed in Pubmed: 22037683.

18. Asadi N, Faraji A, Keshavarzi A, et al. Predictive value of procalcitonin, C-reactive protein, and white blood cells for chorioamnionitis among women with preterm premature rupture of membranes. Int J Gynaecol Obstet. 2019; 147(1): 83-88, doi: 10.1002/ijgo.12907, indexed in Pubmed: 31291474.

19. Oğlak SC, Bademkıran $\mathrm{MH}$, Obut $\mathrm{M}$. Predictor variables in the success of slow-release dinoprostone used for cervical ripening in intrauterine growth restriction pregnancies. J Gynecol Obstet Hum Reprod. 2020; 49(6): 101739, doi: 10.1016/j.jogoh.2020.101739, indexed in Pubmed: 32251738.

20. ACOG Practice Bulletin No. 106: Intrapartum fetal heart rate monitoring: nomenclature, interpretation, and general management principles. Obstet Gynecol. 2009; 114(1): 192-202, doi: 10.1097/AOG.0b013e3181aef106, indexed in Pubmed: 19546798.
21. Obut M, Oğlak SC. Expression of CD44 and IL-10 in normotensive and preeclamptic placental tissue. Ginekol Pol. 2020; 91(6): 334-341, doi: 10.5603/GP.2020.0058, indexed in Pubmed: 32627155.

22. Oglak S, Obut M. Expression of ADAMTS13 and PCNA in the Placentas of Gestational Diabetic Mothers. International Journal of Morphology. 2021; 39(1): 38-44, doi: 10.4067/s0717-95022021000100038.

23. Behram M, Oğlak SC, Doğan Y. Evaluation of BRD4 levels in patients with early-onset preeclampsia. J Gynecol Obstet Hum Reprod. 2021; 50(2): 101963, doi: 10.1016/j.jogoh.2020.101963, indexed in Pubmed: 33129979.

24. Eyerich K, Dimartino V, Cavani A. IL-17 and IL-22 in immunity: Driving protection and pathology. Eur J Immunol. 2017; 47(4): 607-614, doi: 10.1002/eji.201646723, indexed in Pubmed: 28295238.

25. Mühl H, Scheiermann $P$, Bachmann $M$, et al. IL-22 in tissue-protective therapy. Br J Pharmacol. 2013; 169(4): 761-771, doi: 10.1111/bph.12196, indexed in Pubmed: 23530726.

26. Eyerich S, Eyerich K, Pennino D, et al. Th22 cells represent a distinct human $T$ cell subset involved in epidermal immunity and remodeling J Clin Invest. 2009; 119(12): 3573-3585, doi: 10.1172/JCl40202, indexed in Pubmed: 19920355.

27. Wang Y, Xu B, Li MQ, et al. IL-22 secreted by decidual stromal cells and NK cells promotes the survival of human trophoblasts. Int J Clin Exp Pathol. 2013; 6(9): 1781-1790, indexed in Pubmed: 24040442.

28. $\mathrm{Xu} \mathrm{Yi,} \mathrm{Romero} \mathrm{R,} \mathrm{Miller} \mathrm{D,} \mathrm{et} \mathrm{al.} \mathrm{Innate} \mathrm{lymphoid} \mathrm{cells} \mathrm{at} \mathrm{the} \mathrm{hu-}$ man maternal-fetal interface in spontaneous preterm labor. Am J Reprod Immunol. 2018; 79(6): e12820, doi: 10.1111/aji.12820, indexed in Pubmed: 29457302

29. Aris IM, Logan S, Lim C, et al. Preterm prelabour rupture of membranes: a retrospective cohort study of association with adverse outcome in subsequent pregnancy. BJOG. 2017; 124(11): 1698-1707, doi: 10.1111/14710528.14462, indexed in Pubmed: 28029224

30. Sorokin Y, Romero R, Mele L, et al. Maternal serum interleukin-6, C-reactive protein, and matrix metalloproteinase- 9 concentrations as risk factors for preterm birth $<32$ weeks and adverse neonatal outcomes. Am J Perinatol. 2010; 27(8): 631-640, doi: 10.1055/s-0030-1249366, indexed in Pubmed: 20195952. 